\title{
Drosophila terminal structure development is regulated by the compensatory activities of positive and negative phosphotyrosine signaling sites on the Torso RTK
}

\author{
Vaughn Cleghon, ${ }^{1}$ Urte Gayko, ${ }^{2}$ Terry D. Copeland, ${ }^{1}$ Lizabeth A. Perkins, ${ }^{3}$ Norbert Perrimon, ${ }^{2}$ and \\ Deborah K. Morrison ${ }^{1,4}$ \\ ${ }^{1}$ Cellular Growth Mechanisms Section, ABL-Basic Research Program, National Cancer Institute (NCI)-Frederick Cancer \\ Research and Development Center, Frederick, Maryland 21702 USA; ${ }^{2}$ Department of Genetics, Howard Hughes Medical \\ Institute, Harvard Medical School, Boston, Massachusetts 02115 USA; ${ }^{3}$ Pediatric Surgical Research Laboratory, \\ Massachusetts General Hospital, Boston, Massachusetts 02114 USA
}

Specification of cell fates in the nonsegmented terminal regions of developing Drosophila embryos is under the control of a signal transduction pathway mediated by the receptor tyrosine kinase Torso (Tor). Here, we identify tyrosines $(\mathrm{Y}) 630$ and 918 as the major sites of Tor autophosphorylation. We demonstrate that mutation of Y630, a site required for association with and tyrosine phosphorylation of the tyrosine phosphatase Corkscrew, decreases the efficiency of Tor signaling. In contrast, mutation of Y918, a site capable of binding mammalian rasGAP and PLC- $\gamma 1$, increases Tor signaling. Interestingly, when receptors contain mutations in both the Y630 and Y918 sites, Tor signaling is restored to wild-type levels. These results identify a novel mechanism whereby Tor function is regulated using compensatory signals generated from distinct autophosphorylation sites and reveal an underlying signaling pathway for terminal development.

[Key Words: Receptor tyrosine kinase; Drosophila; Torso; Corkscrew]

Received December 13, 1995; revised version accepted January 25, 1996.

The formation of multicellular organisms requires the orchestrated transmission, reception, and propagation of temporal and spatial developmental signals. Many of these signaling events are transduced by proteins of the receptor tyrosine kinase (RTK) family. RTKs function in developmental, mitogenic, and oncogenic signal transduction pathways and in organisms as diverse as mammals, Drosophila melanogaster, and Caenorhabditis elegans (Pawson and Berbstein 1990; Lu et al. 1993b). For many RTKs, binding of the cognate ligand leads to receptor dimerization followed by auto- or transphosphorylation on tyrosine residues (Heldin 1995). This phosphorylation event creates specific docking sites for a variety of cytosolic molecules, such as Src homology 2 (SH2) domain-containing proteins (Cantley et al. 1991; Koch et al. 1991; Cohen et al. 1995/ and phosphotyrosine binding (PTB) domain-containing proteins (Blaikie et al. 1994; Kavanaugh and Williams 1994). Determining the significance and function of receptor-binding events is a key issue in understanding how RTKs transduce such a diverse array of signals. Most studies have addressed this problem by mutating individual RTK phosphorylation (and docking) sites and then assessing the consequences of these mutations on receptor function. Although this

${ }^{4}$ Corresponding author. approach has provided many insights into the molecular mechanisms of RTK-mediated signaling, most of the biological assays employed are based on tissue culture systems rather than on intact organisms in which the RTK actually functions.

Early Drosophila embryogenesis, and in particular, activation of the Torso (Tor) RTK pathway, provides an attractive in vivo model system with which to study the genetic and molecular mechanisms of RTK signal transduction (for review, see Lu et al. 1993b; Duffy and Perrimon, 1994). In the developing Drosophila embryo, activation of the Tor RTK leads to the formation of specialized anterior and posterior terminal structures, termed the acron and telson, respectively (for review, see St. Johnston and Nüsslein-Volhard 1992; Duffy and Perrimon 1994). Although Tor is expressed uniformly throughout the embryo, the protein is activated only in the terminal regions due to the spatially restricted delivery of a diffusible ligand (Casanova and Struhl 1989, 1993; Sprenger and Nüsslein-Volhard 1992). Once Tor is activated, the further transmission of the terminal structure signal has been shown genetically to involve an evolutionarily conserved cassette of signaling molecules including Drk (a Grb2/Sem-5 homolog), Sos, Ras1, Gap1, D-Raf, D-Mek, Rolled (a MAPK homolog), and the SH2 domain-containing tyrosine phosphatase Corkscrew 
(Csw) (for review, see Duffy and Perrimon 1994). Lossof-function (l-o-f) mutations in the terminal class genes result in a reduction or elimination of terminal structures (i.e., a terminal mutant phenotype). Specifically, in the most severe 1-o-f mutations, the anterior head skeleton is collapsed and all structures posterior to abdominal segment 7 (A7) are deleted. Gain-of-function (g-o-f) mutations in the terminal pathway have also been isolated. These lead to an expansion of the terminal regions, at the expense of the central segmented regions, and the subsequent expression of terminal structures in inappropriate areas of the embryo.

The maternally derived Tor pathway regulates the expression of at least two zygotic gap genes, tailless (tIl) and huckebein $(h k b)$ (for review, see Duffy and Perrimon 1994). These genes, which are expressed in defined terminal domains of the embryo, encode transcription factors that further specify development of the terminal regions. Regulation of $t l l$ and $h k b$ expression in the anterior region is complex, involving both the anterior/ bicoid and the terminal/Tor systems. However, in the posterior region, $t l l$ and $h \mathrm{k} b$ expression is controlled solely by the Tor pathway. L-o-f terminal mutations lead to the retraction or elimination of posterior $t l l$ and $h \mathrm{~kb}$ expression, and g-o-f mutations result in posterior expansion of $t l l$ and $h k b$ expression. Furthermore, the severity of terminal 1-o-f and g-o-f mutant phenotypes correlates with changes in the posterior patterns of $t 11$ and $h \mathrm{~kb}$ expression. Therefore, monitoring the expression patterns of these two genes in the posterior domain provides a convenient readout of the strength of the Tor signaling pathway.

In this paper we use a combination of biochemical, molecular, and genetic techniques to study the ability of Tor to propagate a developmental signal in an in vivo, whole organismal setting. Here, we identify two major sites of Tor autophosphorylation, Y630 and Y918, and show that Y630 is essential for interaction with and subsequent phosphorylation of Csw on tyrosine residues. We demonstrate further that the tyrosine phosphorylation of Csw in vivo correlates with the presence of an activated Tor receptor. Finally, by establishing transgenic fly lines expressing only mutant Tor proteins, we provide in vivo evidence that $\mathrm{Y} 630$ is a critical residue involved in the positive transduction of the Tor signal, that Y918 functions as a negative regulator, and that mutation of both of these sites in concert compensates or balances one another.

\section{Results \\ Identification of Tor autophosphorylation sites}

The auto- or transphosphorylation of receptor molecules on tyrosine residues provides an important mechanism whereby mammalian RTKs interact with downstream effector proteins. Therefore, to gain a better understanding of how Tor transduces a signal, we performed experiments to determine the sites of Tor autophosphorylation. For this analysis, immunoprecipitated Tor proteins were washed extensively and allowed to autophosphorylate in vitro in the presence of $\mathrm{Mn}^{2+}$ and $\left[\gamma-{ }^{32} \mathrm{P}\right] \mathrm{ATP}$. Wild-type Tor (Tor ${ }^{\mathrm{WT}}$ ) proteins subjected to this treatment were phosphorylated exclusively on tyrosine residues; however, kinase-inactive Tor (TKM) did not become phosphorylated, indicating that the immunoprecipitates did not contain contaminating kinases capable of phosphorylating Tor (Sprenger et al. 1993). ${ }^{32} \mathrm{P}-\mathrm{La}-$ beled Tor ${ }^{\mathrm{WT}}$ was electrophoresed on SDS-polyacrylamide gels, isolated from the gel matrix, and digested with trypsin. The tryptic phosphopeptides were then separated and eluted from a reverse-phase HPLC C-18 column. When the radioactivity released from the column was quantitated, two major peaks, eluting in fractions 13 and 28, were detected (Fig. 1A). Phosphoamino acid analysis of the peptides contained in these fractions indicated that they were phosphorylated exclusively on tyrosine (data not shown). By subjecting the peptides to automated Edman degradation, we determined that the peptide isolated in fraction 13 was phosphorylated on the fourth residue following the trypsin cleavage site (Fig. $1 \mathrm{~B})$ and that the peptide in fraction 28 was phosphorylated on the eleventh residue (Fig. 1C). When ${ }^{32} \mathrm{P}$-labeled Tor $^{\mathrm{WT}}$ was digested with the proteolytic enzyme LysC (which cleaves only after lysine residues, as opposed to trypsin, which cleaves after lysine and arginine residues), similar peaks and sequence data were obtained /data not shown). To ensure that the identified sites represent activated Tor autophosphorylation sites, these experiments were repeated using the g-o-f Tor ${ }^{4021}$ protein. The results obtained demonstrated that activated $\operatorname{Tor}^{4021}$ autophosphorylates at the same sites and to the same degree as Tor ${ }^{W T}$ (data not shown). Furthermore, no additional sites of phosphorylation were observed on the Tor $^{4021}$ protein (data not shown). From this analysis we conclude that Y630 and Y918 are the sites of phosphorylation, because these are the only tyrosine residues in Tor that are 4 and 11 residues downstream from a trypsin and LysC cleavage site, respectively.

To confirm the identification of these tyrosine residues, we generated mutant Tor proteins that contained tyrosine to phenylalanine substitutions at amino acid positions 630 (Y630F), 918 (Y918F), and 630/918 (YY630/ $918 \mathrm{FF})$. The mutant proteins were then autophosphorylated in vitro, and the phosphorylated tryptic peptides were examined by reverse-phase HPLC. The profile of the radioactivity released during this analysis revealed that Tor ${ }^{\mathrm{Y} 630 \mathrm{~F}}$ contained one major phosphorylated peptide that eluted in fraction 28 (Fig. 1D). In contrast, a peak of radioactivity was not released at fraction 28 for Tor $^{\mathrm{Y} 918 \mathrm{~F}}$, but a major peak was detected in fraction 13 (Fig. 1E). When Tor YY630/918FF was examined, both major peaks at fractions 13 and 28 were missing (Fig. 1F). These data confirm that Y630 and Y918 are the major autophosphorylation sites of Tor and indicate further that the mutant Tor proteins are functional kinases in vitro. In addition, this analysis demonstrates that phosphorylation of Y630 and Y918 is not interdependent and that mutation of these sites does not induce the aberrant phosphorylation of other sites. 
A

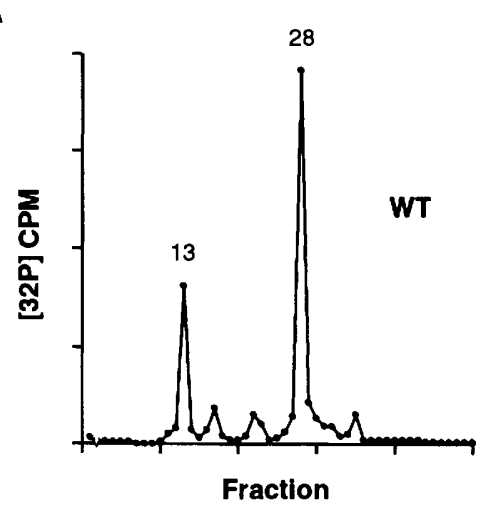

D

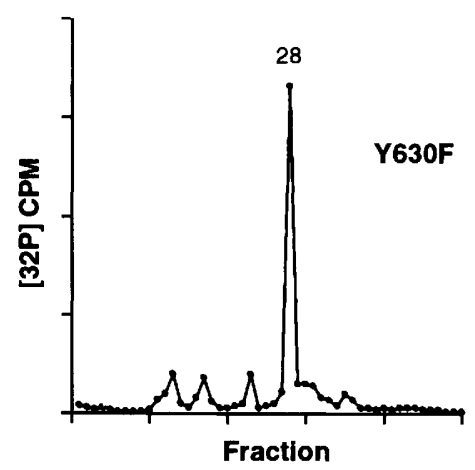

B

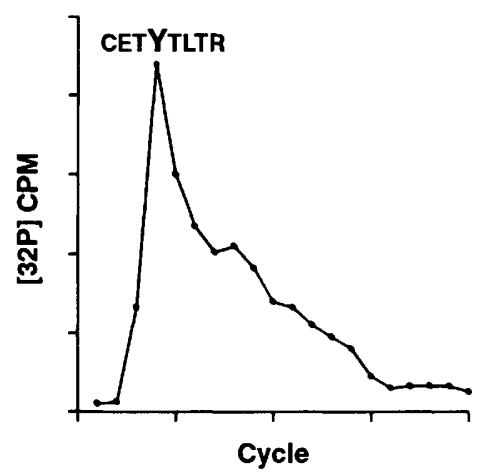

E

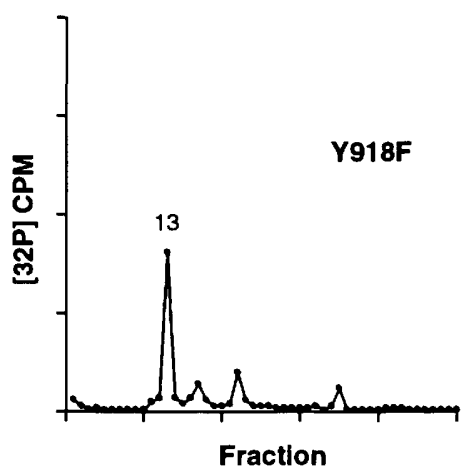

C

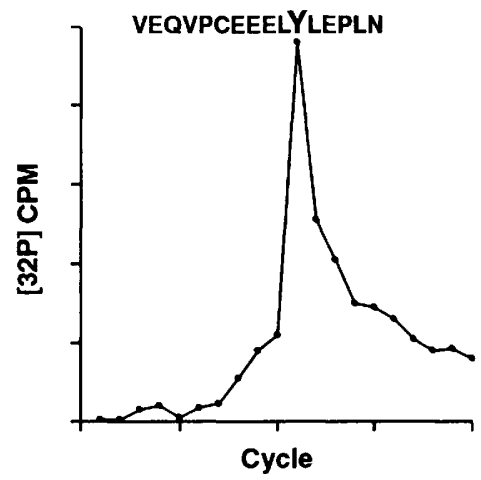

$\mathbf{F}$

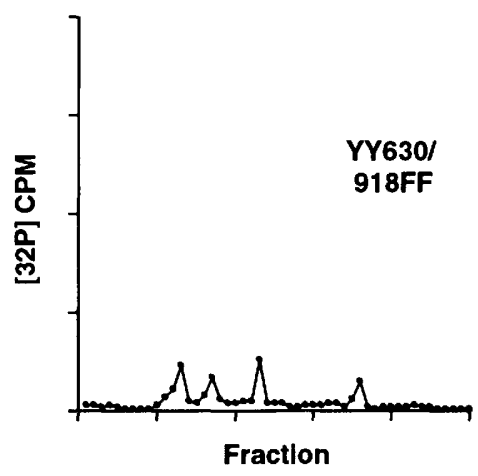

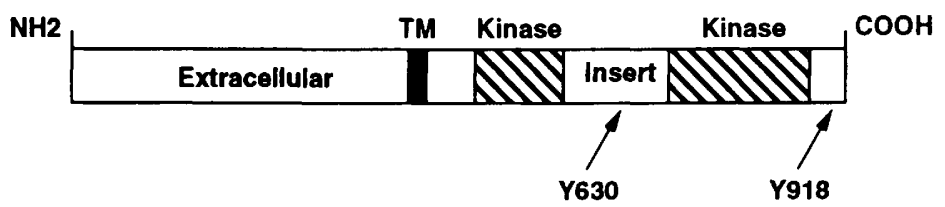

Figure 1. Identification of Tor autophosphorylation sites. In vitro-phosphorylated Tor ${ }^{\mathrm{WT}}$ phosphopeptides were separated by reversephase HPLC, and fractions were collected as described in Materials and methods. Relative amounts of ${ }^{32} \mathrm{P}$ radioactivity in each fraction is shown $(A)$. The isolated Tor ${ }^{\mathrm{WT}}$ peptides from HPLC fractions $13(B)$ and $28(C)$ were then subjected to automated Edman degradation in a spinning-cup sequenator. The relative amount of ${ }^{32} \mathrm{P}$ radioactivity released during each cycle is shown. The sequence of the Tor ${ }^{\mathrm{WT}}$ tryptic peptides identified in fractions 13 and 28, containing Y630 and Y918, is shown in $B$ and $C$, respectively. Reverse-phase HPLC isolation of in vitro-phosphorylated $\operatorname{Tor}^{\mathrm{Y} 630 \mathrm{~F}}(D)$, Tor ${ }^{\mathrm{Y} 918 \mathrm{~F}}(E)$, and $\operatorname{Tor}^{\mathrm{YY} 630 / 918 \mathrm{FF}}(F)$ tryptic peptides is shown. The location of $\mathrm{Y} 630$ and Y918 in the Tor ${ }^{W T}$ molecule is shown schematically at the bottom.

Activated Tor receptors contain binding sites for Csw and other SH2 domain-containing proteins

Phosphotyrosine moieties located in noncatalytic regions of RTKs act as binding sites for a variety of cytosolic signaling molecules, many of which contain $\mathrm{SH} 2$ domains (Cantley et al. 1991; Koch et al. 1991; Cohen et al. 1995). Therefore, to identify proteins that interact with and may be substrates of activated Tor receptors, we performed in vitro binding studies using isolated Tor receptors and various $\mathrm{SH} 2$ domain-containing proteins. For these assays, Tor ${ }^{\mathrm{WT}}$, TKM, Tor ${ }^{\mathrm{Y} 630 \mathrm{~F}}$, Tor ${ }^{\mathrm{Y} 918 \mathrm{~F}}$, and Tor $^{\mathrm{YY} 630 / 918 \mathrm{FF}}$ proteins were immunoprecipitated from Sf 9 cells, washed extensively, and incubated with $\mathrm{Mn}^{2+}$ and ATP to autophosphorylate the potential substrate- binding sites. Similar amounts of the Tor receptors were then incubated with Drosophila Csw and Drk and mammalian PLC $\gamma$ and rasGAP (GAP). The Tor immunoprecipitates were again washed and analyzed for the presence of associated proteins (Fig. 2). By immunoblot analysis, the Drosophila tyrosine phosphatase Csw interacted with activated Tor ${ }^{\mathrm{WT}}$ and Tor ${ }^{\mathrm{Y} 918 \mathrm{~F}}$ but not with TKM or proteins containing the Y630F mutation (Fig. 2). Both mammalian PLC $\gamma$ and GAP were also able to associate with activated Tor ${ }^{\mathrm{WT}}$ but not with TKM or proteins containing the Y918F mutation (Fig. 2). In contrast, Drk, the Drosophila homolog of Grb2, did not interact with any of the Tor receptors (Fig. 2). Together, these results indicate that activated, autophosphorylated Tor can bind Csw, PLC $\gamma$, and GAP. The association with 


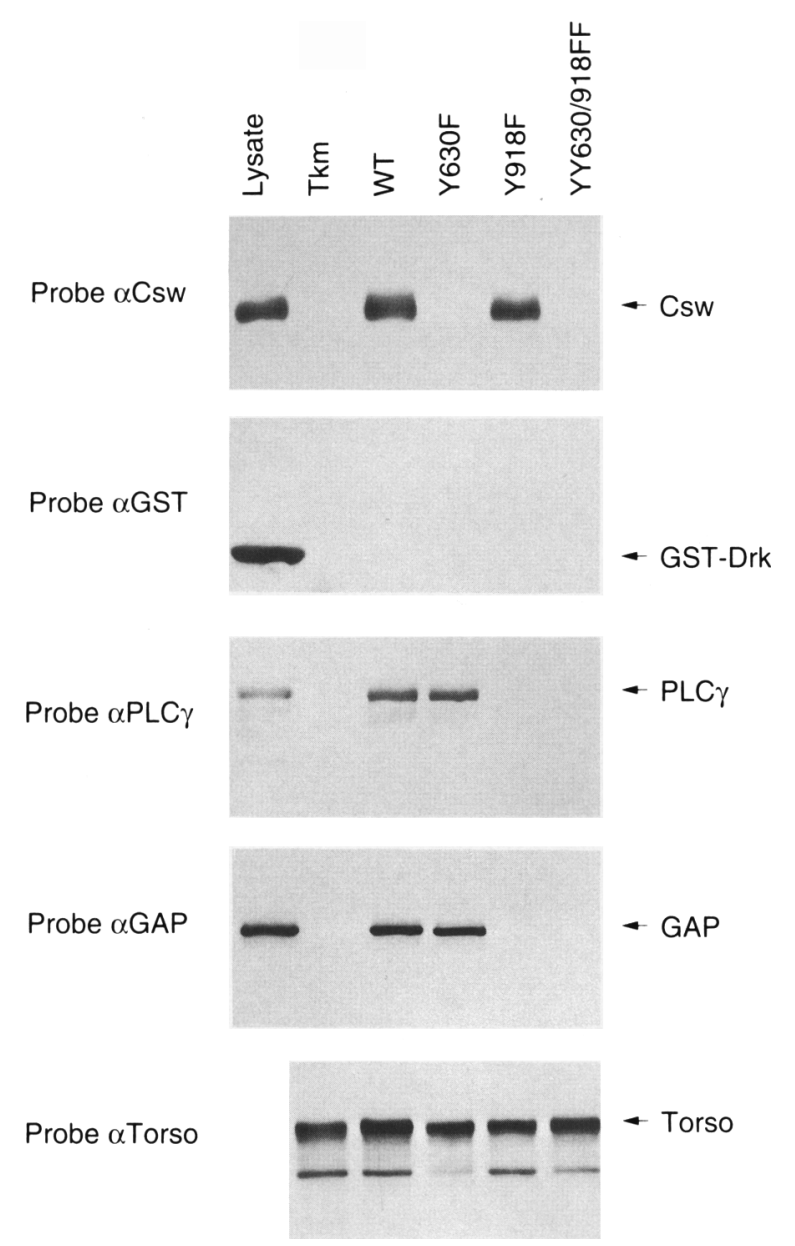

Figure 2. Association of Tor mutants with various $\mathrm{SH} 2$ domain-containing proteins. In vitro binding assays were performed using the various Tor mutants and lysates containing Csw, PLC $\gamma, \mathrm{GAP}$, and a glutathione $S$-transferase/Drk fusion protein (GST-Drk). Proteins associating with the Tor receptors were detected by immunoblot analysis using antibodies recognizing Csw $(\alpha \mathrm{Csw}), \mathrm{GST}(\alpha \mathrm{GST}), \mathrm{PLC} \gamma(\alpha \mathrm{PLC} \gamma)$, and GAP ( $\alpha$ GAP). The Tor immunoprecipitates were subsequently reprobed with Tor antibodies $\{\alpha$ Tor). Samples of the lysates used are included as a control. The Tor mutants examined in this study include kinase-inactive TKM, Tor ${ }^{\mathrm{WT}}(\mathrm{WT})$, and Tor proteins containing tyrosine to phenylalanine substitutions at amino acids 630 (Y630F), 918 (Y918F), and 630/918 (YY630/ 918FF|.

Csw, however, requires the Y630 site, whereas the interaction with PLC $\gamma$ and GAP requires Y918. Although the significance of the association of mammalian PLC $\gamma$ and GAP is unclear, Csw is involved in terminal structure development and has been shown genetically to function downstream of Tor (Perkins et al. 1992).

\section{Csw is a substrate of the Tor RTK}

Because Csw is a component of the Tor signaling pathway and associates with the activated Tor receptor, we then investigated whether Csw becomes tyrosine phosphorylated as a result of this interaction. For this analysis, we examined the phosphorylation state of Csw coexpressed in Sf9 cells with the various Tor mutants. In addition, because the ligand for Tor is unknown and authentic ligand-induced activation of the receptor is not possible, all tyrosine mutations were incorporated into the constitutively activated g-o-f Tor $^{4021}$ protein. By immunoblot analysis using antiphosphotyrosine $(\alpha \mathrm{P}-\mathrm{Tyr})$ antibodies, Csw was found to be phosphorylated on tyrosine residues when coexpressed with activated $\operatorname{Tor}^{4021}$ proteins, but only when the receptor contained the Y630 site (Fig. 3). Mutation of the Y630 site did not simply inactivate the in vivo kinase activity of Tor, because the tyrosine phosphorylation of GAP could be induced following coexpression of GAP with the Y630F mutant (Fig. 3). Thus, these findings suggest that the association with Tor results in the tyrosine phosphorylation of Csw and that Csw is a substrate of Tor.

To determine whether Csw becomes tyrosine phosphorylated as a direct result of Tor ligand-induced activation, we coexpressed Csw with a chimeric Tor receptor containing the extracellular domain of the mammalian Trk /nerve growth factor (NGF) receptor. As controls, Csw was also coexpressed with the constitutively activated Tor $^{4021}$ protein and with the wild-type Trk receptor. Cells were then treated with NGF, and the phosphorylation state of Csw was examined. By immunoblot analysis, treatment with NGF had no effect on the level of tyrosine phosphorylation observed when Csw was coexpressed with activated Tor $^{4021}$ (Fig. 4). Consistent with the observation that SH-PTP2/Syp, the mammalian homolog of Csw, is not a substrate of the Trk receptor (Vambutas et al. 1996), activation of Trk with NGF treatment did not alter the phosphorylation state of Csw (Fig. 4). However, NGF treatment did induce the tyrosine phosphorylation of Csw in cells coexpressing the chimeric Trk-Tor receptor (Fig. 4), demonstrating that ligand-induced activation of the chimeric receptor results in the phosphorylation of Csw on tyrosine residues.

\section{Tyrosine phosphorylation of Csw in Drosophila embryos}

To determine whether Csw is tyrosine phosphorylated in vivo and whether its phosphorylation state correlates with Tor activation, we examined the phosphorylation state of Csw in developing Drosophila embryos. Previously, we showed that Tor ${ }^{\mathrm{WT}}$ is expressed $0-4 \mathrm{hr}$ after egg laying $\left(\right.$ at $\left.27^{\circ} \mathrm{C}\right)$ and that it becomes tyrosine phosphorylated and activated $1-2 \mathrm{hr}$ after egg laying (Sprenger et al. 1993). In contrast, 1-o-f Tor proteins are not tyrosine phosphorylated in vivo and lack kinase activity, whereas g-o-f Tor proteins are constitutively tyrosine phosphorylated and activated (Sprenger et al. 1993). Therefore, for this analysis, we examined the tyrosine phosphorylation state of Csw isolated from embryos derived from females homozygous for the l-o-f $t o r^{W K}$ and g-o-f tor $^{4021}$ mutations. Csw proteins were immunopre- 


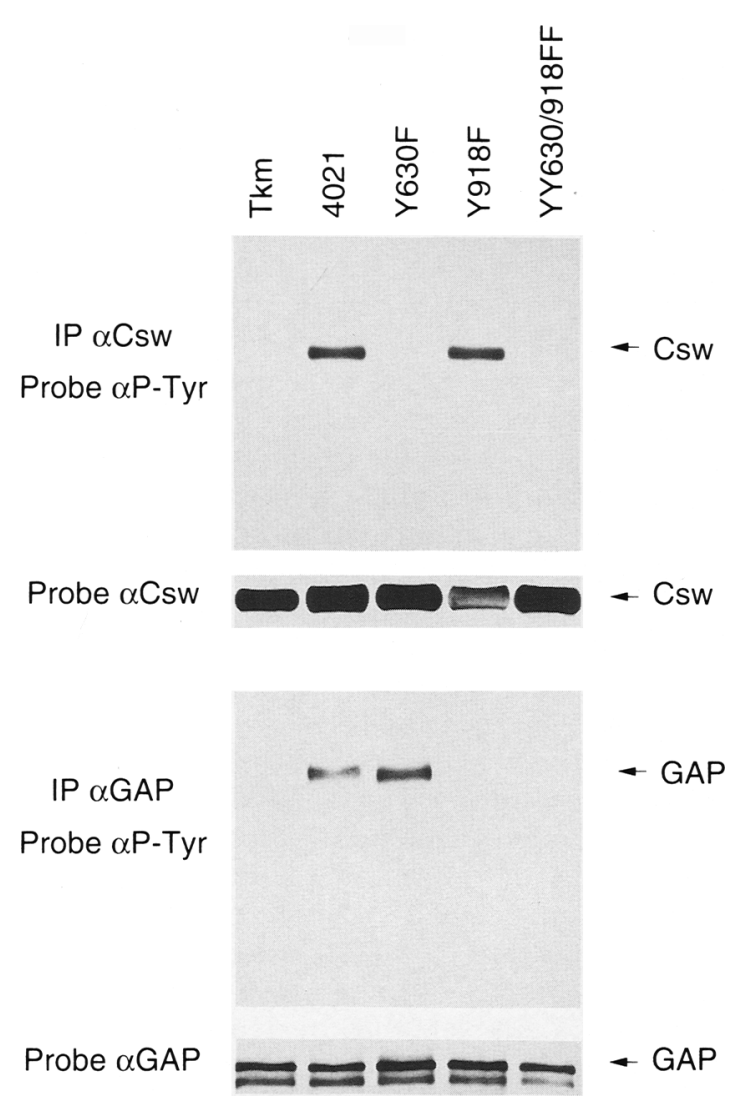

Figure 3. Csw is tyrosine phosphorylated when expressed with activated Tor receptors containing the $\mathrm{Y} 630$ site. Sf9 cells were infected with Csw alone or were coinfected with Csw and the various Tor mutant receptors. At $48 \mathrm{hr}$ postinfection, Sf9 cells were lysed, Csw proteins were immunoprecipitated (IP), and the immunoprecipitates were examined by immunoblot analysis using antibodies recognizing phosphotyrosine ( $\alpha \mathrm{P}-\mathrm{Tyr})$ or Csw $(\alpha \mathrm{Csw})$. A similar analysis was performed using a recombinant GAP-expressing baculovirus and an antibody recognizing GAP ( $\alpha$ GAP). The Tor mutants examined in this study include kinase-inactive TKM, activated Tor ${ }^{4021}$ (4021), and activated Tor $^{4021}$ containing tyrosine to phenylalanine substitutions at amino acids 630 (Y630F), 918 (Y918F), and 630/918 (YY630/ 918FF).

cipitated from embryos collected at $0-3$ and $12-24 \mathrm{hr}$ after egg laying and examined by immunoblot analysis using $\alpha \mathrm{P}$-Tyr antibodies. The tyrosine phosphorylation of Csw was observed only in tor ${ }^{4021}$ embryos and only at the time of Tor expression (0-3 hr) (Fig. 5). In addition, the tyrosine phosphorylation of Csw was found to be coincident with the tyrosine phosphorylation of the g-o-f Tor $^{4021}$ protein (Fig. 5). These results indicate that Csw is tyrosine phosphorylated in vivo and that its phosphorylation state correlates with the expression of an activated Tor protein.

\section{In vivo function of $\mathrm{Y} 630$ and $\mathrm{Y} 918$}

To determine the roles of the Y630 and Y918 autophosphorylation sites in Tor-mediated signal transduction, we examined in vivo the signaling activities associated with the corresponding tor mutants. For this analysis, the $\mathrm{Y} 630 \mathrm{~F}$ and $\mathrm{Y} 918 \mathrm{~F}$ mutations were incorporated into an $11.5-\mathrm{kb} \mathrm{tor}^{+}$genomic fragment that fully rescues tor 1-o-f mutations (see Materials and methods). To eliminate completely other sources of Tor expression, the Tor mutant receptors were expressed in the background of $\operatorname{tor}^{X R 1}$, a protein null allele (Sprenger et al. 1989, 1993). The signaling abilities of the Tor mutant proteins were then determined by measuring the spatial expression domains of $t l l$ and $h k b$ and by examining the embryonic cuticles. In these studies the control Tor $^{\mathrm{WT}}\left(\mathrm{P}\left[\right.\right.$ tor $\left.\left.^{+}\right]\right)$ fully rescued the terminal phenotypes associated with tor $^{X R 1}$ (Table 1). In addition, as was observed previously by Casanova and Struhl (1989), the amount of Tor in wild-type embryos appeared to greatly exceed the level needed for terminal cell fate specification in that decreasing the copy number of $P\left[\right.$ tor $\left.^{+}\right]$did not affect the expression of $t l l$ and $h k b$. Examination of embryos derived from females that expressed $P\left[\right.$ tor $\left.^{Y 630 F}\right]$ revealed that $\mathrm{Y} 630$ was involved in the positive transmission of the Tor signal. As shown in Table 1, expression of this mutant allele decreased the domain of tll expression by $15.6 \%$ (reduced to $12.45 \%$ EL in Tor $^{\mathrm{Y}}{ }^{630 \mathrm{~F}}$ from $14.75 \%$ in wild type; Fig. $6 \mathrm{C}$ ) and $h k b$ expression by $31 \%$ (reduced to $5.7 \% \mathrm{EL}$ in Tor ${ }^{\mathrm{Y} 630 \mathrm{~F}}$ from $8.25 \%$ in wild type; Fig. 6D). Furthermore, the embryonic cuticle phenotype resembled a l-o-f function terminal phenotype (Fig. $7 \mathrm{C}$ ).

The Y918 site, however, appeared to act as a negative regulator of Tor signaling. As indicated in Table 1, embryos derived from females that carried two copies of $P\left[\right.$ tor $\left.^{Y 918 F}\right]$ showed a clear expansion of the expression domains of both $t 11$ (by $19 \%$; Fig. 6E) and $h k b$ (by $11.5 \%$; Fig. 6 F). Expansion of the expression domain of the terminal gap genes toward the center of the embryo was shown previously to be associated with the repression of abdominal segmentation (Steingrimsson et al. 1991). Therefore, as expected, embryos derived from $P\left[\right.$ tor $\left.^{Y 918 F}\right]$ females contained abdominal segment defects that were reminiscent of those associated with tor g-o-f mutations (Fig. 7D-F; for review, see Duffy and Perrimon 1994). Interestingly, the ectopic expression of both $t l l$ and $h k b$ was less pronounced in the presence of a single copy of $P\left[\right.$ tor $^{Y 918 F}$ ] (see Table 1), an effect most likely attributable to the difference in the amount of activated receptor present in the embryo.

To determine the effect of removing both a positive and negative signaling site from the Tor receptor, we generated a transgene that contained the YY630/918FF double mutation. As shown in Table 1, mutation of both sites appeared to compensate for one another, because the expression domains of both $t l l$ and $h k b$ were similar to those of wild type. This finding was observed regardless of whether the transgenic lines expressed one or two copies of $P\left[\right.$ tor $\left.^{Y Y 630 / 918 F F}\right]$. In addition, when the embryonic cuticle phenotype was examined, the cuticle structures of the tor ${ }^{Y Y 630 / 918 F F}$ embryos resembled that of wild type. From this analysis, the only difference detected between tor ${ }^{Y Y 630 / 918 F F}$ and tor ${ }^{W T}$ embryos was in the percentage of animals that reached adulthood, which 


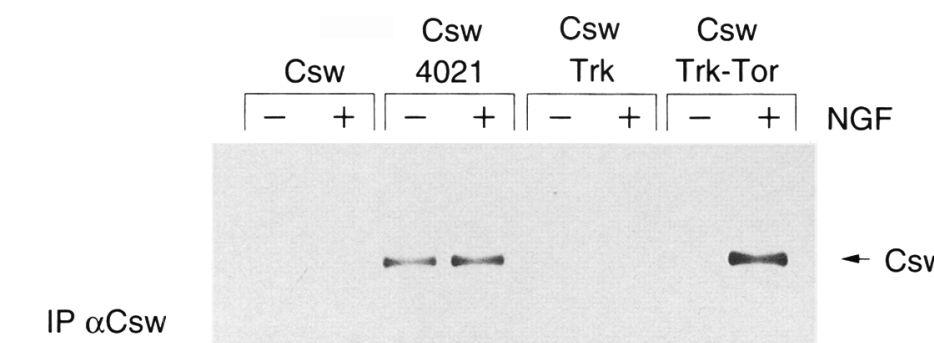

Probe $\alpha$ P-Tyr

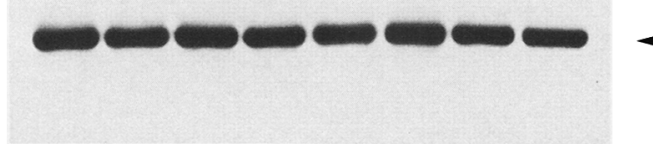

$\lg G$
Figure 4. Csw is tyrosine phosphorylated in response to ligand-induced activation of Tor. Sf 9 cells were infected with Csw alone or were coinfected with Csw and Tor ${ }^{4021}$, Trk, or the chimeric Trk/Tor (Trk-Tor) receptor. At 24 hr postinfection, Sf9 cells were treated $(+)$ or not treated $(-)$ with NGF for $10 \mathrm{~min}$ at $30^{\circ} \mathrm{C}$. The cells were then lysed, Csw proteins were immunoprecipitated, and the immunoprecipitates were examined by immunoblot analysis using $\alpha \mathrm{P}$-Tyr antibodies. in $\operatorname{tor}^{Y Y 630 / 918 F F}$ embyros was reduced by $55 \%$ (data not shown). Together, these results indicate that receptors containing the YY630/918FF mutations are comparable to wild type in Tor signaling.

\section{Discussion}

In this study we have examined the contribution of individual sites of tyrosine phosphorylation in regulating the ability of the Tor RTK to transduce a developmental signal. By protein sequencing techniques, we identified two major sites of autophosphorylation, Y630 and Y918 (Fig. 1). Y630 is located within the kinase insert region of the Tor receptor, whereas Y918 lies near the carboxyl terminus. Both sites were found to be crucial for the correct specification of terminal cell fate in developing Drosophila embryos. One site, Y630, serves to positively transduce the Tor signal, whereas the second site, Y918, functions as a negative effector. Elimination of both sites, however, had a compensating effect, restoring to a
A

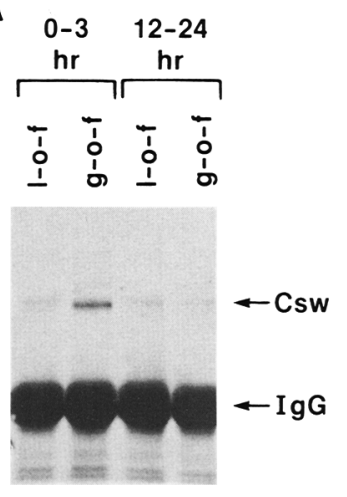

B

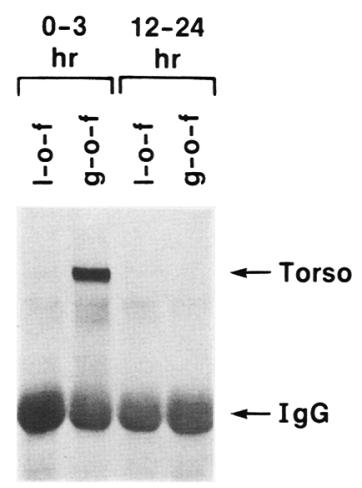

Figure 5. Csw is tyrosine phosphorylated in Tor g-o-f but not l-o-f embryos. Embryos expressing l-o-f tor ${ }^{W K}$ and g-o-f tor ${ }^{4021}$ alleles were collected at various times after egg laying, and lysates were prepared. Csw $(A)$ and Tor $(B)$ proteins were immunoprecipitated from the lysates and examined by immunoblot analysis using $\alpha \mathrm{P}$-Tyr antibodies. large degree the imbalance resulting from the individual mutations.

\section{Csw associates with Y630 to positively transduce the} Tor signal

Our studies indicate that Y630 functions in the positive transmission of the Tor signal. Embryos expressing Tor ${ }^{\mathrm{Y} 630 \mathrm{~F}}$ proteins exhibited an l-o-f terminal phenotype that included a reduction in the posterior expression of both $t l l$ and $h k b$ and a corresponding reduction in cuticular elements. The Y630F mutation impairs but does not completely block Tor signaling, because in tor null mutants there is a complete lack of $t l l$ and $h k b$ expression posteriorly (Weigel et al. 1990; Pignoni et al. 1992; Lu et al. 1993b). Thus, there must be at least one other region on Tor, in addition to $\mathrm{Y} 630$, that serves to positively transduce the Tor signal.

How does Y630 exert its influence? For many RTKs, autophosphorylation sites in noncatalytic regions function as docking sites for a variety of cytosolic signaling molecules that contain SH2 (Cantley et al. 1991; Koch et al. 1991; Cohen et al. 1995) or PTB (Blaikie et al. 1994; Kavanaugh and Williams 1994) domains. Given the precedent in mammalian systems, Y630 and Y918 would be expected to serve as binding sites for downstream signaling molecules involved in terminal structure development. All of our findings suggest that Y630 functions as a binding site for the $\mathrm{SH} 2$ domain-containing, nonreceptor protein tyrosine phosphatase Csw and that Csw may be a substrate of Tor. In vitro binding studies showed that Csw could associate with activated tyrosine phosphorylated Tor receptors but only when Y630 was present. Using the baculovirus/Sf9 expression system, we found that Csw was tyrosine phosphorylated when coexpressed with activated $\mathrm{g}$-o-f Tor proteins containing Y630. In addition, by using a chimeric Trk-Tor receptor, we were able to show that Csw was phosphorylated following ligand-induced activation of Tor. These results appear to reflect in vivo signaling events, because Csw immunoprecipitated from developing Drosophila em- 
Table 1. Expression of tll and hkb in Tor mutant embryos

\begin{tabular}{|c|c|c|c|c|c|c|c|c|c|}
\hline \multirow[b]{2}{*}{ Genetic background } & \multirow{2}{*}{$\begin{array}{c}\text { Copy } \\
\text { no. }\end{array}$} & \multicolumn{3}{|c|}{ tll Expression } & \multicolumn{3}{|c|}{$h k b$ Expression } & \multicolumn{2}{|c|}{ Hatching rates } \\
\hline & & no. & $\operatorname{EL}(\%)$ & S.E.M. & no. & EL $(\%)$ & S.E.M. & no. & hatched $(\%)$ \\
\hline Wild type & & 44 & 15.0 & 0.18 & 30 & 8.2 & 0.2 & 227 & 88 \\
\hline \multirow[t]{2}{*}{ tor $^{+}$} & 1 & 45 & 14.7 & 0.14 & 48 & 8.3 & 0.12 & 198 & 80 \\
\hline & 2 & 51 & 14.8 & 0.13 & 39 & 8.2 & 0.13 & 450 & 84 \\
\hline \multirow[t]{2}{*}{ tor $^{Y 630 F}$} & 1 & 39 & 12.5 & 0.22 & 49 & 5.8 & 0.19 & 388 & 45 \\
\hline & 2 & 49 & 12.4 & 0.23 & 53 & 5.6 & 0.18 & 318 & 47 \\
\hline \multirow[t]{2}{*}{$\operatorname{tor}^{Y 918 F}$} & 1 & 35 & 15.4 & 0.2 & 47 & 9.0 & 0.15 & 240 & 16 \\
\hline & 2 & 37 & 17.6 & 0.3 & 36 & 9.3 & 0.3 & 150 & 4 \\
\hline \multirow[t]{2}{*}{$\operatorname{tor}^{Y 630+918 F}$} & 1 & 60 & 15.1 & 0.11 & 49 & 8.4 & 0.14 & 650 & 88 \\
\hline & 2 & 45 & 15.2 & 0.2 & 44 & 8.4 & 0.17 & 430 & 90 \\
\hline
\end{tabular}

The spatial domain of expression of $t l l$ and $h k b$ was measured in various genetic backgrounds. Wild type is the Oregon $R$ strain. tor ${ }^{+}$

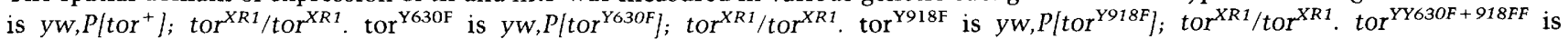
$y w, P\left[\right.$ tor $^{Y Y 630+918 F F}$; tor $^{X R 1} /$ tor $^{X R 1}$. (no.) Number of embryos scored in each experiment. The domain of expression of both $t l l$ and $h k b$ was determined as the percentage of egg length (EL) and the standard deviation (S.E.M.) for each sample size is indicated. The hatching rates were determined as the number of hatching larvae divided by the total number of fertilized eggs. A fraction of the tor ${ }^{\mathrm{Y} 630 F}$ animals was able to hatch from the egg case and give rise to viable adults. These were most likely derived from the embryos that showed the less severe reduction in both $t l l$ and $h k b$ expression.

bryos was tyrosine phosphorylated when expressed with an activated but not an inactive form of the Tor kinase.

Results examining transgenic flies are also consistent with Y630 functioning as a docking site for Csw. Csw has been identified by genetic studies as a positive transducer of the terminal pathway acting downstream of Tor (Perkins et al. 1992). If Y630 is the Csw docking site, then elimination of this residue would be expected to produce a phenotype similar to that resulting from the loss of Csw protein. This is indeed the case; however, the domain of expression of the terminal gap genes is not as severely affected in tor $^{Y 630 F}$ embryos as in csw mutant animals. This discrepancy in severity of phenotypes could be accounted for by the ability of Csw to interact indirectly with the Tor receptor at other sites. Alternatively, it is possible that the genetically null $\operatorname{csw} \mathrm{mu}-$ tants examined previously (Perkins et al. 1992) do not correspond to protein null mutations and that dominant-
Figure 6. Effect of the tor phosphotyrosine mutants on the expression of $t l l$ and $h k b$. Expression patterns of tll $\langle A, C, E)$ and $h k b$ $(B, D, E)$ are shown in embryos derived from mothers of the following genotypes: wild type $(A, B) ;$ y $w, P\left[\right.$ tor $\left.^{\mathrm{Y} 630 F}\right] / \mathrm{y} w, P\left[\right.$ tor $\left.^{Y 630 F}\right]$; tor $^{X R 1} /$ tor $^{X R 1}(C, D)$; and $y w, P /$ tor $\left.^{Y 918 F}\right] / y w$, $P\left[\right.$ tor $\left.^{Y 918 F}\right]$; tor ${ }^{X R 1 / \text { tor }^{X R 1}}(E, F)$. The domains of $t l l$ and $h \mathrm{~kb}$ expression indicates as percentage of egg length $\langle E L|$, with $0 \%$ corresponding to the posterior pole. The reduction in the domains of expression of both $t 11$ and $h k b$ associated with tor $^{Y 63 O F}$ reveals that this tyrosine is required for positive signaling from Tor. The increase in the domains of expression of both tll and $h k b$ associated with tor $^{Y 918 F}$ demonstrates that this tyrosine is critical for down-regulating the activity of Tor.

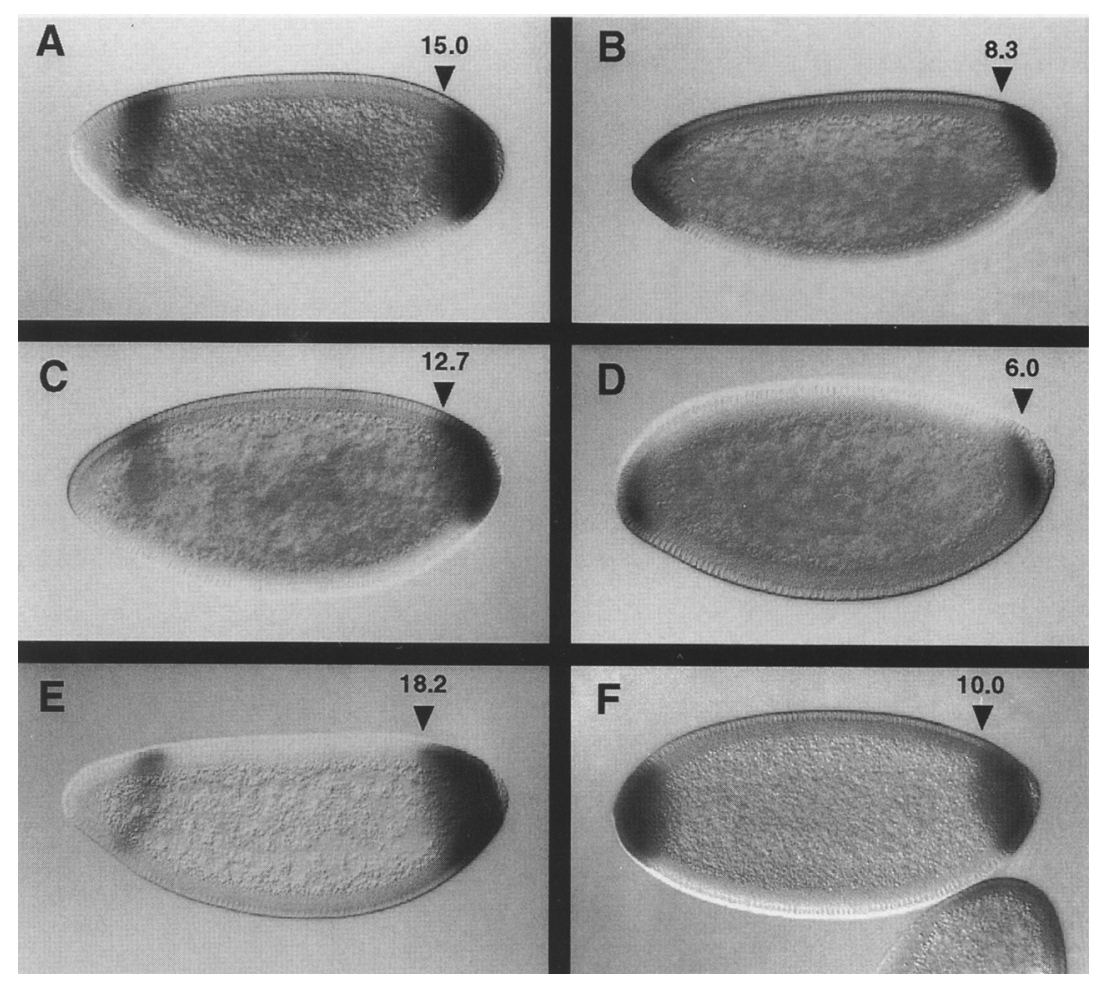



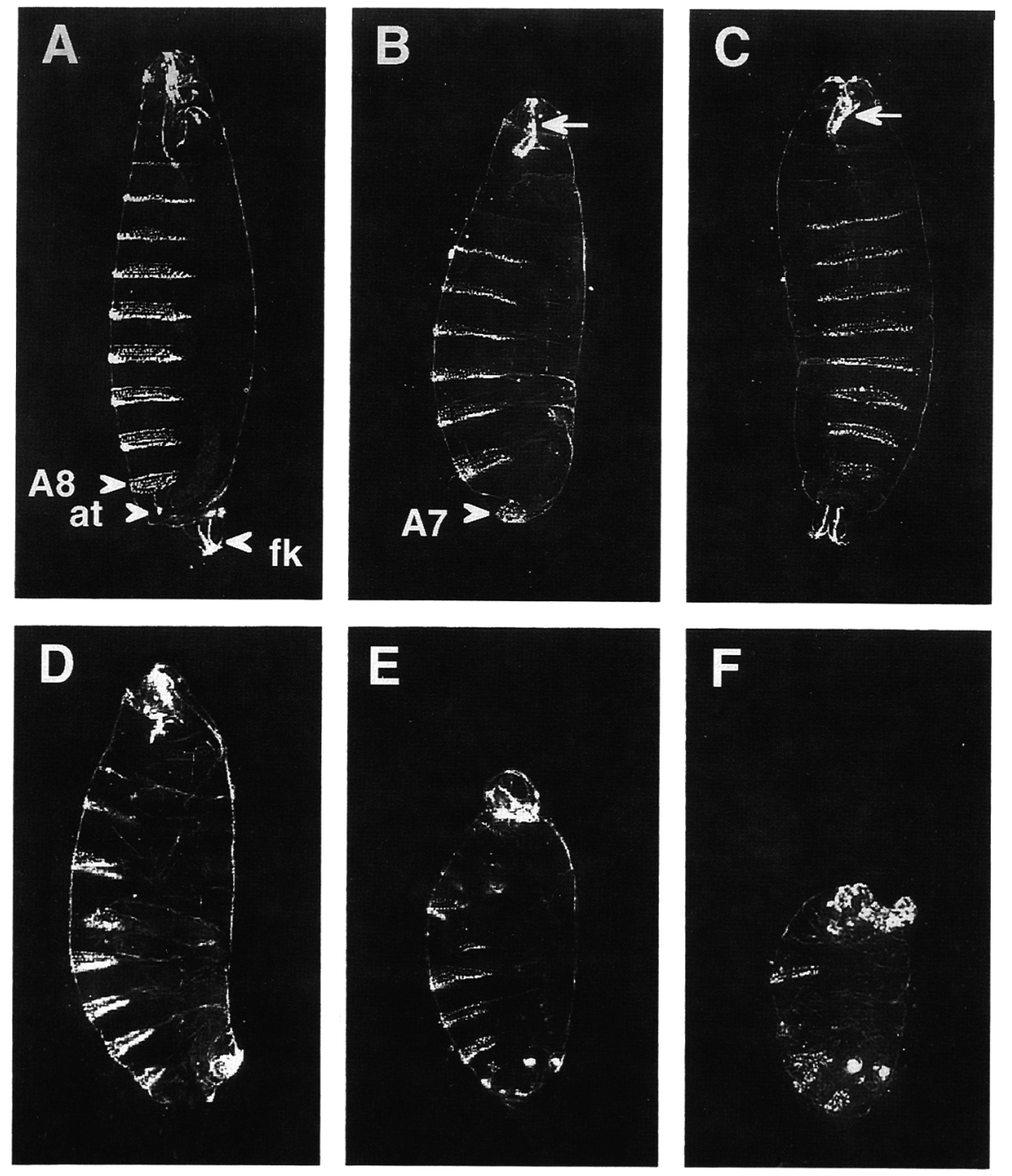

Figure 7. Effect of the tor phosphotyrosine mutants on embryonic development. Cuticle phenotypes of embryos derived from females of the following genotypes are shown: wild type $(A)$; tor $^{X R 1 /}$ tor $^{X R 1}(B), y w, P\left[\right.$ tor $\left.^{Y 630 F}\right] / y$ w, P[tor $\left.{ }^{Y 630 F}\right]$; tor $^{X R 1 / \text { tor }^{X R 1}}(C)$; and $y w, P\left[\right.$ tor $\left.^{Y 918 F}\right] / y w$, $P /$ tor $\left.^{Y 918 F}\right]$; $\operatorname{tor}^{X R 1} /$ tor $^{X R 1}(D-F)$. In the tor $^{X R 1}$ l-o-f phenotype $(B)$, embryos show defects both anteriorly and posteriorly. In these embryos, the labrum, A8, and telson are missing and the head skeleton is collapsed. Embryos derived from tor ${ }^{X R 1}$ females that carry one or two copies of $P /$ tor $^{Y 630 F}$ / partially rescue the tor terminal defects. In the embryo shown in $C$, the defects are associated with the head skeleton and the partial rescue of A8. No differences in the embryonic phenotypes are detected, regardless of whether the females carry one or two copies of $P\left[\right.$ tor $\left.^{Y 630 F}\right]$. Embryos derived from tor ${ }^{X R 1}$ females that carry one or two copies of $P\left[\right.$ tor $\left.^{Y 918 F}\right]$ exhibit a tor $\mathrm{g}-\mathrm{o}-\mathrm{f}$ phenotype $(D-F)$. These embryos are associated with different degrees of deletion of the abdominal segments, and the extent of the defects is stronger with two copies of the P element. Abbreviations: (A7 and A8) the positions of the abdominal 7 and $8 \mathrm{seg}$ ments, respectively; (fk) Filzkörper; (at) anal tuft. negative effects, which would further reduce the signaling activity of Tor, could be associated with these mutant Csw proteins.

The direct association of Csw with activated Tor is similar to results reported for the vertebrate homologs of Csw, SH-PTP2/Syp. Like Csw, the vertebrate homologs have been shown to associate with a variety of activated RTKs to positively transduce RTK-mediated signals (Lechleider et al. 1993; Milarski and Saltiel 1994; Noguchi et al. 1994; Xiao et al. 1994; Tang et al. 1995), and in certain instances, they become phosphorylated on tyrosine in response to RTK activation (Feng et al. 1993; Vogel et al. 1993/. As with the vertebrate homologs, the actual mechanism of Csw action is unclear. Catalytic activity appears necessary for both Csw and SH-PTP2/Syp to transduce developmental signals in Drosophila and Xenopus, respectively (L.A. Perkins, unpubl.; Tang et al. 1995). No substrates for these phosphatases have been identified in Drosophila or Xenopus, although in a recent report the mammalian PDGF $\beta$-receptor was identified as a putative substrate of SH-PTP2/ Syp (Klinghoffer and Kazlauskas 1995). Similarly, the function of Csw tyrosine phosphorylation remains ambiguous. In one report phosphorylation appeared to have a modest activating effect on the catalytic activity of SH-PTP2/Syp (Vogel et al. 1993), whereas in a second report phosphorylation had no effect (Feng et al. 1993). Furthermore, elimination of the two known phosphorylation sites in the carboxy-terminal tail of SH-PTP2/Syp (one of which is conserved in Csw) had no observable effect on the ability of the protein to propagate a fibroblast growth factor (FGF)-mediated signal in Xenopus development (Tang et al. 1995). An alternative function for Csw tyrosine phosphorylation may be to allow Csw to function as an adaptor protein linking the Tor signal to Ras activation. Ras activation by many RTKs involves the binding of a Grb2(Drk)-Sos complex to an autophosphorylated YXNX motif within the RTK (Songyang et al. 1993). The platelet-derived growth factor (PDGF) receptor activates Ras, in part, through an interaction with SH-PTP2/Syp, which contains several YXNX sequences (Bennett et al. 1994; Li et al. 1994). Tor does not contain the Grb2/Drk binding site, and as our results show, Drk does not appear to associate directly 
with Tor. However, one of the YXNX motif phosphorylation sites identified in SH-PTP2/Syp (Bennett et al. 1994) is a conserved site of phosphorylation in Csw (V. Cleghon and D.K. Morrison, unpubl.), indicating that Csw may also function as an adaptor protein linking Tor signaling to Ras activation. Consistent with this model, previous studies have implicated Ras activation as an important component in the terminal pathway (Lu et al. 1993a). In addition, Drk mutant embryos (Hou et al. 1995) display l-o-f terminal phenotypes that resemble those of both $c s W$ null and tor ${ }^{Y 63 O F}$ mutants. Taken together, our evidence suggests strongly that Y630 functions as a positive transducer of the Tor signal and that this effect is mediated by the binding of Csw. Furthermore, our results support the model linking Csw with Ras activation.

\section{The role of Y918 as a negative effector of the Tor signal}

Y918 appears to be a negative effector of the terminal pathway. Embryos expressing Tor ${ }^{\mathrm{Y} 918 \mathrm{~F}}$ display a g-o-f terminal phenotype that is characterized by expanded $t l l$ and $h k b$ expression posteriorly and increased terminal cuticular structures. What is the nature of the Y918 negative effector? All available information suggests that Y918 functions as a binding site for downstream signaling molecules. Of the two $\mathrm{SH} 2$ domain-containing proteins that have been shown to function in the terminal pathway, Csw (Perkins et al. 1992) and Drk (Hou et al. 1995), neither associates with the Y918 site. However, our experiments did show that Y918 could serve as a specific binding site for the mammalian signaling proteins PLC $\gamma$ and GAP. In addition, both mammalian proteins were phosphorylated on tyrosine when coexpressed in Sf9 cells with kinase-active Tor containing Y918 (Fig. 3 ; data not shown). From these findings, we postulate that the Drosophila counterparts of these proteins may be involved in the Tor signaling pathway. A Drosophila PLCy homolog containing two tandem $\mathrm{SH} 2$ domains was recently described (Emori et al. 1994), although no l-o-f phenotype has been attributed to this protein. In mammalian signaling pathways, PLC $\gamma$ typically functions in the positive transmission of RTK signals; however, there is a precedent for GAP to function as a negative effector. In an analysis of substrate-binding sites on the murine PDGF receptor, the GAP-binding site suppressed PDGF-induced mitogenesis (Valius et al. 1995). One function of GAP is to stimulate the endogenous GTPase activity of Ras, thereby regulating the level of active GTP-bound Ras and inactive GDP-bound Ras (Boguski and McCormick 1993). Therefore, the association of a Drosophila GAP would provide a model whereby Y918 could function as a negative regulator by limiting Ras activation. A Drosophila homolog of GAP, Gapl (Gaul et al. 1992), has been implicated genetically to be involved in the Tor pathway (Hou et al. 1995). Inactivation of the Gap1 locus in germ-line mosaics results in embryos exhibiting a g-o-f phenotype similar in severity to that of the tor ${ }^{Y 918 F}$ mutant. Although Gapl is an attractive candidate for the negative effector that binds to
Y918, this protein, unlike the mammalian homolog used in our studies, does not contain an SH2 domain /Gaul et al. 1992); therefore, direct binding of Gapl to Y918 seems unlikely. However, an SH2 domain-containing adaptor molecule could conceivably link Gapl to Tor, just as Drk links Sos to RTK-mediated activation of Ras. Alternatively, other Drosophila GAP proteins, in addition to Gap1, may exist that do contain $\mathrm{SH} 2$ domains. Finally, our studies do not rule out the possibility that other, as yet unidentified, proteins bind at the Y918 site and serve as negative effectors of the Tor signal.

\section{Compensating effect of $\mathrm{Y} 630$ and $\mathrm{Y} 918$}

Perhaps most intriguing of all is our finding that mutation of both major autophosphorylation sites results in near-wild-type patterns of $t l l$ and $h k b$ posterior expression and apparently normal terminal cuticular structures. Clearly, alteration of either Y630 or Y918 individually has a profound effect on the ability of Tor to transmit a terminal signal. However, removal of the positive effector site, Y630, in conjunction with the simultaneous removal of Y918, does not block transduction of the Tor signal. Therefore, at least one additional positive pathway for Tor signal transmission, which does not depend on the binding of substrates to the Y630 and Y918 sites, must exist. The increased strength of the positive signal transmitted by the Tor ${ }^{\mathrm{YY} 630 / 918 \mathrm{FF}}$ mutant compared with the Tor ${ }^{\mathrm{Y} 630 \mathrm{~F}}$ mutant substantiates further the existence of another underlying and as yet unidentified receptor-activated pathway. Such a pathway may be initiated by substrate recognition of unique receptor sequences or of minor autophosphorylation sites. Whereas Y630 and Y918 represent the major sites of tyrosine phosphorylation, our mapping studies indicate that additional minor sites do exist and are qualitatively and quantitatively unaltered in all of our Tor phosphorylation site mutants (see Fig. 1). However, the lower levels of phosphorylation may not reflect the contribution that these sites make to the propagation of the Tor signal, because little is known concerning the stoichiometry of phosphorylation and the relative affinities of cytosolic signaling molecules for their binding sites in vivo. It is therefore quite possible that minor phosphorylation sites also play a role in the positive transmission of the Tor signal and that the influence of the minor sites could expand once the major phosphorylation sites are removed.

The compensating effect of the YY630/918FF mutation in restoring near-wild-type development is consistent with a model in which the Y630 and Y918 sites serve as a single control element that is comprised of both positive and negative effectors of the Rasl pathway and that functions in addition to another, as yet unidentified, receptor-activated pathway. In this scenario, Csw binding to the Y630 site would represent the positive effector linking Tor activation to Ras activation through the binding of Drk and Sos, whereas a GAP protein binding to the Y918 site would provide negative regulation by attenuating Ras activity. Perturbing the control element 
by removing either the positive or negative regulatory element would result in the delivery of too much or too little signal. However, removing the entire regulatory element would leave the main signaling sequence intact and capable of delivering a normal signal. The elaboration of the Tor signaling complex by the addition of positive and negative regulatory elements may provide an important mechanism whereby the delivery of the terminal signal can be modulated precisely.

In conclusion, our results indicate that the Tor receptor contains phosphotyrosine residues that function in the positive and negative transmission of the Tor signal. These sites appear to exert their influence by binding to specific downstream effector molecules. These findings demonstrate that the delivery of a balanced signal is crucial for proper terminal structure development and emphasize further that it is not only the effectors themselves that are important but also the timing and particular mix of Tor-associated proteins that determine the efficacy of the signal.

\section{Materials and methods}

\section{Antibodies}

The Tor antibody is a rabbit polyclonal antibody directed against the cytoplasmic domain of Tor (Sprenger et al. 1993). The Csw antibody is a rabbit polyclonal antibody generated against a purified synthetic peptide corresponding to amino acid residues 423-440 of Csw. The PLCy antibody is a murine monoclonal antibody (Suh et al. 1988). The GAP antibody was generated by immunizing rabbits with a bacterial fusion protein containing amino acid residues 171-448 of human GAP (Upstate Biotechnology Incorporated).

\section{Construction of mutant Tor proteins and generation} of recombinant baculoviruses

cDNA clones encoding tor ${ }^{W T}$ and tor ${ }^{4021}$ alleles (pBtor, pB4021, respectively; Sprenger et al. 1993) were digested with BamHI and EcoRI. Fragments containing the entire Tor coding sequences were inserted into the NcoI-EcoRI cloning sites of the pGem-7Zf (Promega) plasmid. Tor constructs encoding amino acid point mutations were generated by site-directed mutagenesis as described previously (Fabian et al. 1993), using pGemTor and the appropriate oligonucleotides to introduce the desired base changes. The specific base changes in all mutant constructs were confirmed by sequence analysis. cDNA fragments encoding the entire wild-type and mutant Tor proteins were isolated and inserted into the $\mathrm{pAcC} 4$ baculoviral transfer vector for expression in Sf9 cells. For generation of the Csw-expressing baculovirus, BamHI linkers were first inserted into the wildtype Csw cDNA clone (Perkins et al. 1992) immediately upstream of the initiating ATG codon and downstream of the TGA terminator codon. The BamHI fragment encoding the Csw protein was then cloned into the pVL941 baculoviral transfer vector for expression in $\mathrm{Sf} 9$ cells.

\section{Expression of recombinant Tor proteins, preparation of cellular lysates, and immunoprecipitation assays}

Routinely, for recombinant protein production, $2 \times 10^{6}$ Sf9 cells were infected with the desired baculovirus at a multiplicity of infection of 10. At $48 \mathrm{hr}$ postinfection, Sf9 cells were washed twice with ice-cold phosphate-buffered saline (PBS) and lysed for $20 \mathrm{~min}$ at $4^{\circ} \mathrm{C}$ in $500 \mu$ l of Nonidet P-40 (NP-40) lysis buffer containing $20 \mathrm{~mm}$ Tris $\{\mathrm{pH} 8.01,137 \mathrm{~mm} \mathrm{NaCl}, 10 \%$ glycerol, $1 \%$ NP-40, 1 mM phenylmethylsulfonyl fluoride, aprotinin $\mid 0.15$ $\mathrm{U} / \mathrm{ml}$, $20 \mu \mathrm{M}$ leupeptin, and $5 \mathrm{~mm}$ sodium vanadate. Insoluble material was removed by centrifugation at $4^{\circ} \mathrm{C}$ for $10 \mathrm{~min}$ at $10,000 \mathrm{~g}$, and cell lysates were equalized for Tor protein expression by immunoblot analysis. For Drosophila embryo extracts, flies were grown and collected as described previously (Sprenger et al. 1993). A 0.05-gram aliquot of the collected embryos was then resuspended in $1 \mathrm{ml}$ of NP-40 lysis buffer, homogenized with six strokes in a ground-glass dounce homogenizer (Wheaton), and incubated on ice for $15 \mathrm{~min}$. Insoluble material was removed from the lysates as described above. Immunoprecipitation assays were performed by incubating lysates with the appropriate antibody for $3 \mathrm{hr}$ at $4^{\circ} \mathrm{C}$. Protein A/G beads (Santa Cruz Biotechnology, Inc.) were used to collect the antigen-antibody complexes. The immunoprecipitates were then washed four times with cold lysis buffer before analysis.

\section{In vitro kinase assays and phosphoamino acid analysis}

Tor immunoprecipitates were washed three times with NP-40 lysis buffer containing $1 \mathrm{~mm}$ sodium vanadate and once with kinase buffer [30 mM HEPES at $\mathrm{pH} 7.4,10 \mathrm{~mm} \mathrm{MnCl}_{2}, 5 \mathrm{~mm}$ $\mathrm{MgCl}_{2}, 1 \mathrm{~mm}$ dithiothreiotol (DTT), $5 \mu \mathrm{M}$ ATP]. The complexes were then incubated at $25^{\circ} \mathrm{C}$ for $15 \mathrm{~min}$ in $40 \mu \mathrm{l}$ of kinase buffer containing $20 \mu \mathrm{Ci}$ of $\left[\gamma^{-32} \mathrm{P}\right] \mathrm{ATP}$. Kinase assays were terminated by the addition of gel loading buffer ( $4 \%$ SDS, $80 \mathrm{~mm} \mathrm{DTT}, 10 \%$ glycerol), the samples were resolved by SDS-polyacrylamide gel electrophoresis (SDS-PAGE), and the phosphoproteins were visualized by autoradiography. For phosphoamino acid analysis, labeled proteins were transferred to Immobilon membranes after electrophoresis, visualized by autoradiography, excised, and hydrolyzed directly with $5.7 \mathrm{~N} \mathrm{HCl}$ for $70 \mathrm{~min}$ at $110^{\circ} \mathrm{C}$. The recovered phosphoamino acids were analyzed at $\mathrm{pH} 1.9$ and $\mathrm{pH}$ 3.5 .

\section{Reverse-phase HPLC}

${ }^{32} \mathrm{P}$-Labeled proteins were separated by SDS-PAGE, eluted from the gel matrix, precipitated with trichloroacetic acid, and digested with trypsin or LysC. Aliquots of the digested proteins were lowered to $\mathrm{pH} 2.0$ with $20 \%$ trifluoroacetic acid (TFA) and loaded onto a Waters $3.9 \times 300 \mathrm{~mm} \mathrm{C18}$ column. The chromatography was performed in an LKB chromatography system with two 2150 HPLC pumps, a 2152 LC controller, and a 2140 rapid spectral detector. When buffer salts began to elute, the column was developed with an increasing gradient of acetonitrile in $0.05 \%$ aqueous TFA. The stepwise gradient at a flow rate of $1 \mathrm{ml} / \mathrm{min}$ was $0 \%-40 \% \mathrm{CH}_{3} \mathrm{CN}$ over $60 \mathrm{~min}, 40 \% \mathrm{CH}_{3} \mathrm{CN}$ for $10 \mathrm{~min}, 40 \%-60 \% \mathrm{CH}_{3} \mathrm{CN}$ over $10 \mathrm{~min}$, and $60 \% \mathrm{CH}_{3} \mathrm{CN}$ for $10 \mathrm{~min}$. Fractions were collected at 1 -min intervals, and Cerenkov counted for ${ }^{32} \mathrm{P}$ radioactivity in a Beckman LS 5801 scintillation counter.

\section{Edman degradation}

Semiautomated amino-terminal sequence analysis was performed in a Beckman $890 \mathrm{C}$ spinning cup sequencer. Polybrene (2.5 mg, Aldrich) was applied to the spinning cup along with 120 nmoles of the dipeptide Tyr-Glu and subjected to four cycles of Edman degradation. Equine apomyoglobin ( 9 nmoles) along with the ${ }^{32} \mathrm{P}$-containing peptide in $\mathrm{CH}_{3} \mathrm{CN}$-water was then added to the spinning cup, dried, and subjected to 20 cycles with no prewashes. Aliquots of the butyl chloride solutions of the amino acid thiazoline derivatives in cycles 2 and 11 were removed to monitor the sequencing of the apomyoglobin. The 
remainder of each butyl chloride fraction was transferred to a glass scintillation vial, blown dry in a chemical hood with air under a heat lamp, redissolved in $6 \mathrm{ml}$ of PCS (Amersham), allowed to equilibrate in the dark in the scintillation counter for at least $2 \mathrm{hr}$, and counted for $20 \mathrm{~min}$.

\section{In vitro association assays}

Tor proteins were expressed in Sf9 cells and immunoprecipitated as described above. The immunopreciptated Tor proteins were washed twice with NP-40 lysis buffer containing $0.1 \%$ SDS and $0.5 \%$ deoxycholate, twice with NP-40 lysis buffer, and twice with $10 \mathrm{~mm}$ Tris $(\mathrm{pH} 7.4)$. Complexes were then incubated with $30 \mathrm{~mm}$ HEPES at $\mathrm{pH} 7.4,10 \mathrm{mM} \mathrm{MnCl}_{2}, 1 \mathrm{~mm} \mathrm{DTT}$, $100 \mu \mathrm{M} \mathrm{ATP}$, and $200 \mu \mathrm{M}$ sodium vanadate for $30 \mathrm{~min}$ at $25^{\circ} \mathrm{C}$. Following the kinase reaction, the immunoprecipitates were incubated for $2 \mathrm{hr}$ at $4^{\circ} \mathrm{C}$ with lysates prepared from cells lysed in NP-40 lysis buffer. The complexes were then washed three times with NP-40 lysis buffer and once with $10 \mathrm{mM}$ Tris (pH 7.4) before immunoblot analysis.

\section{Generation of transgenic flies}

The pGem Tor cDNAs encoding either the wild-type or mutant Tor proteins (Y630F, Y918F, YY630/918FF) were used to generate various P-element transformants. The $X m n I-A s e I$ fragment of the cDNAs was cloned into the 11.5 -kb EcoRI-EcoRI genomic tor DNA, which was shown previously to fully rescue the tor null phenotype (Casanova and Struhl 1989). The constructs were then cloned into CasPeR4, which contains the marker mini-white (C.S. Thummel, pers. comm.; Thummel et al. 1988). P-element-mediated transformation was performed according to Spradling (1986) following injection into the delta2.3 transposase strain (Robertson et al. 1988). Transformant lines with insertions on the $\mathrm{X}$ chromosome were used to generate flies that carry one or two copies of the $P\left[\right.$ tor $\left.^{+}\right]$construct in a tor ${ }^{X R 1}$ background. Similar results were obtained with multiple independent transformant lines (data not shown). $\operatorname{tor}^{X R 1}$ contains a deletion within the tor gene and does not produce RNA or protein (Sprenger et al. 1989, 1993)

\section{Examination of embryos}

Embryos were collected at $0-3 \mathrm{hr}$ and prepared for in situ hybridization using digoxygenin-labeled probes as described by Tautz and Pfeifle (1989). Single-stranded sense and antisense digoxigenin-containing DNA probes were prepared by the polymerase chain reaction labeling technique using appropriate primers (Biolabs). Probes were prepared from plasmids containing the $t l l$ (Pignoni et al. 1990) and $h k b$ (Weigel et al. 1990) cDNAs. For visualization, embryos were mounted in glycerol. Subsequently, embryos were analyzed and photographed with a Zeiss Axiophot microscope equipped with Nomarski optics. Embryonic cuticles were prepared in Hoyer's mountant as described by van der Meer (1977) from 24- to 36-hr-old embryos.

\section{Acknowledgments}

We thank R. Stephens for providing baculovirus constructs expressing wild-type Trk and the chimeric Trk-Tor receptors, F. Sprenger for providing $\mathrm{pBtor}$ and tor mutant embryos, J. Casanova and G. Struhl for providing genomic tor DNA, P. Olivier and T. Pawson for providing the GST-Drk construct, and K. Mathes for excellent technical assistance. U. G. was supported in part by the Gotlieb Carl and Daimler Benz Foundation. Work in the Perrimon laboratory was supported by funds from the National Science Foundation (IBN-9506237) and the Howard Hughes Medical Institute. Work in the Morrison laboratory was sponsored by the National Cancer Institute, DHHS, under contract with ABL.

The publication costs of this article were defrayed in part by payment of page charges. This article must therefore be hereby marked "advertisement" in accordance with 18 USC section 1734 solely to indicate this fact.

\section{References}

Bennett, A.M., T.L. Tang, S. Sugimoto, C.T. Walsh, and B.J. Neel. 1994. Protein-tyrosine-phosphatase SHPTP2 couples platelet-derived growth factor receptor beta to Ras. Proc. Natl. Acad. Sci. 91: 7335-7339.

Blaikie, P., D. Immanuel, J. Wu, N. Li, V. Yajnik, and B. Margolis. 1994. A region in Shc distinct from the SH2 domain can bind tyrosine phosphorylated growth factor receptors. $J$. Biol. Chem. 269: 32031-32034.

Boguski, M.S. and F. McCormick. 1993. Proteins regulating Ras and its relatives. Nature 336: 643-654.

Cantley, L.C., K.R. Auger, C. Carpenter, B. Duckworth, A. Graziani, R. Kapeller, and S. Soltoff. 1991. Oncogenes and signal transduction. Cell 64: 281-302.

Casanova, J. and G. Struhl. 1989. Localized surface activity of torso, a receptor tyrosine kinase, specifies terminal body pattern in Drosophila. Genes \& Dev. 3: 2025-2038.

- 1993. The torso receptor localizes as well as transduces the spatial signal specifying terminal body pattern in Drosophila. Nature 362: 152-155.

Cohen, G.B., R. Ren, and D. Baltimore. 1995. Modular binding domains in signal transduction proteins. Cell 80: 237-248.

Duffy, J.B. and N. Perrimon. 1994. The torso pathway in Drosophila: Lessons on receptor protein tyrosine kinase signaling and pattern formation. Dev. Biol. 166: 380-395.

Emori, Y., R. Sugaya, H. Akimaru, S.-I. Higashijima, E. Shishido, K. Saigo, and Y. Homma. 1994. Drosophila phospholipase $\mathrm{C}-\gamma$ expressed predominantly in blastoderm cells at cellularization and in endodermal cells during later embryonic stages. J. Biol. Chem. 269: 19474-19479.

Fabian, J.R., I.O. Daar, and D.K. Morrison. 1993. Critical tyrosine residues regulate the enzymatic and biological activity of Raf-1 kinase. Mol. Cell. Biol. 13: 7170-7179.

Feng, G.-S., C.-C. Hui, and T. Pawson. 1993. SH2-containing phosphotyrosine phosphatase as a target of protein-tyrosine kinases. Science 259: 1607-1610.

Gaul, U., G. Mardon, and G.M. Rubin. 1992. A putative Ras GTPase activating protein acts as a negative regulator of signaling by the sevenless receptor tyrosine kinase. Cell 68: $1007-1019$.

Heldin, C.-H. 1995. Dimerization of cell surface receptors in signal transduction. Cell 80: 213-223.

Hou, X.S., T.-B. Chou, M.B. Melnick, and N. Perrimon. 1995. The Torso receptor tyrosine kinase can activate Raf in a Ras-independent pathway. Cell 81: 63-71.

Kavanaugh, W.M. and L.T. Williams. 1994. An alternative to $\mathrm{SH} 2$ domains for binding tyrosine-phosphorylated proteins. Science 266: 1862-1865.

Klinghoffer, R.A. and A. Kazlauskas. 1995. Identification of a putative Syp substrate, the PDGF $\beta$ receptor. J. Biol. Chem. 270: 22208-22217.

Koch, C.A., D. Anderson, M.F. Moran, C. Ellis, and T. Pawson. 1991. SH2 and SH3 domains: Elements that control interactions of cytoplasmic signaling proteins. Science 252: 668674. 
Lechleider, R.J., S. Sugimoto, A.M. Bennett, A.S. Kashishian, J.A. Cooper, S.E. Shoelson, C.T. Walsh, and B.G. Neel. 1993. Activation of the $\mathrm{SH} 2$-containing phosphotyrosine phosphatase SH-PTP2 by its binding site, phosphotyrosine 1009 , on the human platelet-derived growth factor receptor $\beta$. J. Biol. Chem. 268: 21478-21481.

Li, W., R. Nishimura, A. Kashishian, A.G. Batzer, W.J.H. Kim, J.A. Cooper, and J. Schlessinger. 1994. A new function for a phosphotyrosine phosphatase: Linking Grb2-Sos to a receptor tyrosine kinase. Mol. Cell. Biol. 14: 509-517.

Lu, X., T.-B. Chou, N.G. Williams, T. Roberts, and N. Perrimon. 1993a. Control of cell fate determination by $\mathrm{p} 21^{\text {ras }} /$ Ras 1 : An essential component of torso signaling in Drosophila. Genes \& Dev. 7: 621-632.

Lu, X., L.A. Perkins, and N. Perrimon. 1993b. The torso pathway in Drosophila: A model system to study receptor tyrosine kinase signal transduction. Development (Suppl.) 4756.

Milarski, K.L. and A.R. Saltiel. 1994. Expression of catalytically inactive Syp phosphatase in 3T3 cells blocks stimulation of mitogen-activated protein kinase by insulin. I. Biol. Chem. 269: 21239-21243.

Noguchi, T., T. Matozaki, K. Horita, Y. Fujioka, and M. Kasuga. 1994. Role of SH-PTP2, a protein-tyrosine phosphatase with Src homology 2 domains, in insulin-stimulated Ras activation. Mol. Cell. Biol. 14: 6674-6682.

Pawson, T. and A. Berbstein. 1990. Receptor tyrosine kinases: Genetic evidence for their role in Drosophila and mouse development. Trends Genet. 6: 350-356.

Perkins, L.A., I. Larsen, and N. Perrimon. 1992. corkscrew encodes a putative protein tyrosine phosphatase that functions to transduce the terminal signal from the receptor tyrosine kinase torso. Cell 70: 225-236.

Pignoni, F., R.M. Baldarelli, E. Steingrimsson, R.J. Dias, A. Patapoutian, J.R. Merriam, and J.A. Lengyel. 1990. The Drosophila gene tailless is expressed at the embryonic termini and is a member of the steroid receptor superfamily. Cell 62: 151-163.

Pignoni, F., E. Steingrimsson, and J.A. Lengyel. 1992. bicoid and the terminal system activate tailless expression in the early Drosophila embryo. Development 115: 239-251.

Robertson, H.M., C.R. Preston, R.W. Phillis, D. JohnsonSchlitz, W.K. Benz, and W.R. Engels. 1988. A stable genomic source of P-element transposase on Drosophila melanogaster. Genetics 118: 461-470.

Songyang, Z., S.E. Shoelson, M. Chaudhuri, G. Gish, T. Pawson, W.G. Haser, F. King, T. Roberts, S. Ratnofsky, R.J. Lechleider, B.G. Neel, R.B. Birge, J.E. Fajardo, M.M. Chou, H. Hanafusa, B. Schaffhausen, and L.C. Cantley. 1993. SH2 domains recognize specific phosphopeptide sequences. Cell 72: 767-778.

Spradling, A. 1986. P-element mediated transformation. In Drosophila, a practical approach (ed. D.B. Roberts), pp. 175198. Oxford IRL Press, London, UK.

Sprenger, F. and C. Nüsslein-Volhard. 1992. Torso receptor activity is regulated by a diffusible ligand produced at the extracellular terminal regions of the Drosophila egg. Cell 71: 987-1001.

Sprenger, F., L.M. Stevens, and C. Nüsslein-Volhard. 1989. The Drosophila gene torso encodes a putative receptor tyrosine kinase. Nature 338: 478-483.

Sprenger, F., M.M. Trosclair, and D.K. Morrison. 1993. Biochemical analysis of torso and D-raf during Drosophila embryogenesis: Implications for terminal signal transduction. Mol. Cell. Biol. 13: 1163-1172.

St. Johnston, D. and C. Nüsslein-Volhard. 1992. The origin of pattern and polarity in the Drosophila embryo. Cell 68: 201219.

Steingrimsson, E., F. Pignoni, G.-J. Liaw, and J.A. Lengyel. 1991. Dual role of the Drosophila pattern gene tailless in embryonic termini. Science 254: 418-421.

Suh, P.-G., S.H. Ryu, K.S. Cho, K.Y. Lee, and S.G. Rhee. 1988. Monoclonal antibodies to three phospholipase $\mathrm{C}$ isozymes from bovine brain. J. Biol. Chem. 263: 14497-14504.

Tang, T.L., R.M. Freeman Jr., A.M. O'Reilly, B.J. Neel, and S.Y. Sokol. 1995. The SH2-containing protein-tyrosine phosphatase SH-PTP2 is required upstream of MAP kinase for early Xenopus development. Cell 80: 473-483.

Tautz, D. and C. Pfeifle. 1989. A non-radioactive in situ hybridization method for the localization of specific RNAs in Drosophila embryos reveals translational control of the segmentation of hunchback. Chromosome 98: 81-85.

Thummel, C.S., A.M. Boulet, and H.D. Lipshitz. 1988. Vectors for Drosophila P-element-mediated transformation and tissue culture transfection. Gene 74: 445-456.

Valius, M., J.P. Secrist, and A. Kazlauskas. 1995. The GTPaseactivating protein of Ras suppresses platelet-derived growth factor $\beta$ receptor signaling by silencing phospholipase C- $\gamma \mathrm{l}$. Mol. Cell. Biol. 15: 3058-3071.

Vambutas, V., D.R. Kaplan, M.A. Sells, and J. Chernoff. 1996. Nerve growth factor stimulates tyrosine phosphorylation and activation of Src homology-containing protein tyrosine phosphatase 1 in PC12 cells. J. Biol. Chem. (in press).

van der Meer, F. 1977. Optical clean and permanent whole mount preparation for phase-contrast microscopy of cuticular structures of insect larvae. Dros. Inf. Serv. 52: 160.

Vogel, W., R. Lammers, J. Huang, and A. Ullrich. 1993. Activation of a phosphotyrosine phosphatase by tyrosine phosphorylation. Science 259: 1611-1614.

Weigel, D., G. Jürgens, M. Klingler, and H. Jäckle. 1990. Two gap genes mediate maternal terminal pattern information in Drosophila. Science 248: 495-498.

Xiao, S., D.W. Rose, T. Sasaoka, H. Maegawa, T.R. Burke, Jr., P.P. Roller, S.E. Shoelson, and J.M. Olefsky. 1994. Syp (SH-PTP2) is a positive mediator of growth factor-stimulated mitogenic signal transduction. J. Biol. Chem. 269: 21244 21248. 


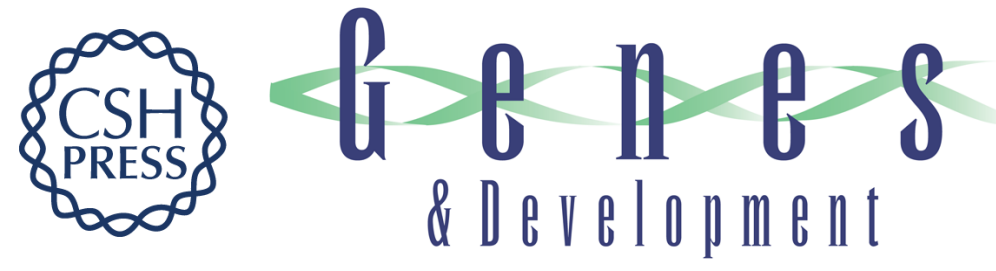

\section{Drosophila terminal structure development is regulated by the compensatory activities of positive and negative phosphotyrosine signaling sites on the Torso RTK.}

V Cleghon, U Gayko, T D Copeland, et al.

Genes Dev. 1996, 10:

Access the most recent version at doi:10.1101/gad.10.5.566

References This article cites 42 articles, 23 of which can be accessed free at: http://genesdev.cshlp.org/content/10/5/566.full.html\#ref-list-1

License

Email Alerting Receive free email alerts when new articles cite this article - sign up in the box at the top Service right corner of the article or click here.

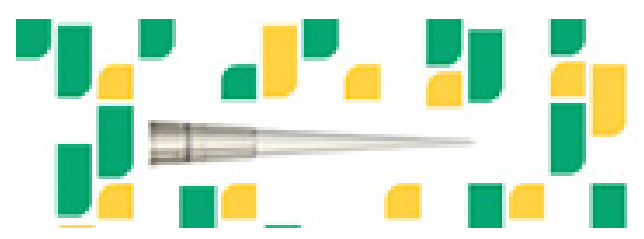

Focused on your science. 